\title{
Aproveitamento de resíduos de chapas de madeiras reconstituídas alinhadas ao Eco design
}

\author{
RYMSZA, Elizabet Zenni; Pós-graduado; UTFPR \\ elizenni@yahoo.com.br \\ PERUSSI, Marcelo; Pós-graduado; UTFPR \\ marceloperussi@ufpr.br \\ TREIN, Fabiano André; Pós- Doutor; UFPR \\ fabianotrein@feevale.br
}

Use of reconstituted wood sheet residues aligned with ECO design

\section{Resumo}

O artigo apresenta estudos direcionados ao descarte dos resíduos sólidos gerados pelas indústrias moveleiras de pequeno porte de Curitiba e Região Metropolitana do Estado do Paraná. Essas indústrias são grandes consumidoras de chapas de madeira reconstituída em MDF que, em seu processo produtivo, gera volumes cumulativos de sobras desse tipo de materiais. Para encontrar uma adequada alternativa no aproveitamento destes resíduos sólidos são apresentados dados coletados através de pesquisa de casos já desenvolvidos e de análise de novas possibilidades de utilização sob a ótica dos conceitos de Logística Reversa e Economia Circular. Este estudo também propõe uma alternativa econômica viável para a indústria, chegando até a economia social, gerando novas oportunidades de emprego e fonte de renda, no qual poderá colaborar com a diminuição do volume de resíduos descartados direto ao meio ambiente, projetando um ciclo de vida prolongado aos resíduos e transformando-o em economia circular.

Palavras-chave: Ciclo de vida; Economia Circular; Eco design.

\section{Abstract}

The article presents studies aimed at the disposal of solid waste generated by the furniture industries from small to medium Porte de Curitiba and Metropolitan Region of the State of Paraná. These industries are big consumers of MDF and MDP reconstituted wood sheets in their production processes, that is, in their furniture manufacturing, generating cumulative volumes of left over's from these types of materials (solid waste). In order to find an adequate alternative in the use of these solid wastes, we present data collected through research of already developed cases and analysis of new possibilities of use, from the perspective of the concepts of Reverse Logistics and Circular Economy. This study also proposes a viable economic alternative for the industry, reaching the social economy, generating new employment opportunities and a source of income, in which it can collaborate to reduce the volume of waste disposed of directly to the environment, designing a life cycle waste and transforming it into a circular economy.

Keywords: Life Cycle; Circular Economy; Eco design. 


\section{Introdução}

As indústrias de móveis produzem uma significativa porcentagem de resíduos sólidos na confecção de seus produtos. Seu gerenciamento e destinação são de extrema importância, principalmente, quanto à destinação final de resíduos que já não têm mais a possibilidade de aplicação em outras usabilidades além daquelas para as quais foram concebidos. Um exemplo disso é o MDF, muito utilizado nas pequenas indústrias de móveis.

Os painéis reconstituídos de madeira representam um mercado em ascensão, recebendo investimentos na casa dos bilhões de dólares no Brasil no ano de 2014 (ABIPA, 2014a).

Atualmente sabe-se da necessidade da responsabilidade das indústrias e da sociedade em darem o destino correto aos seus resíduos, visto que é preciso cada vez mais diminuir os impactos gerados por esse grande volume de resíduos ao meio. Isso pode às vezes gerar grandes estoques por não haver boas propostas de reutilização dos descartes indevidos, ocorrendo falta de interesse na reutilização.

A demanda crescente das empresas moveleiras quanto à necessidade de adequar seus produtos às exigências legais e comerciais de implantação de requisitos ambientais, as tem motivado a reavaliarem os seus sistemas produtivos do ponto de vista da sustentabilidade (RAPÔSO et al, 2011, p. 9).

Já existem processos e meios de se fazer este aproveitamento de resíduos através da reciclagem, a qual pode recuperar a funcionalidade. $\mathrm{O}$ produto ou algumas de suas partes podem ser reutilizados para a mesma função ou mesmo para outra função, podendo ser pré-fabricado ou reprocessado, selecionando materiais que permitem serem reconstruídos em um novo produto.

Outro fator que atinge diretamente estes resíduos é a perda financeira, pois a no ato de compra de matéria-prima pelas indústrias não se faz o pagamento apenas daquilo que se aproveita na produção.

A forma como se faz aplicação do formato de um componente de um produto sobre uma chapa de madeira, papelão etc., por exemplo, contribui para diminuir a quantidade de resíduos, aparas e rebarbas. Assim, ao analisar a produção de resíduos de madeira gerada, identificar suas características, quantidade e dimensionamento após a transformação primária, bem como identificando como está sendo seu descarte e reaproveitamento é possível desenvolver um novo produto. Ou seja, verifica-se que há a possibilidade de reaproveitamento pela própria indústria criadora dentro de suas características produção.

Os resíduos podem ser reutilizados em diversos tipos de produtos ou pequenos objetos, até mesmo móveis decorativos - de acordo com as dimensões destes resíduos sólidos -, além de possibilitar o aproveitamento total da matéria-prima, que se transforma em insumo novamente. Isso contribui com a diminuição do descarte aos aterros e queima, eliminando a possibilidade de contaminação ambiental e acúmulo de resíduos sólidos dentro das empresas.

Visando conformidade com a Lei no. 12305/2010, artigo 3ㅇ inciso IV - ciclo de vida do produto: série de etapas que envolvem o desenvolvimento do produto, a obtenção de matériasprimas e insumos, o processo produtivo, o consumo e disposição final; e na preocupação de como é feita a transformação e o descarte da matéria-prima na produção de móveis das pequenas indústrias de Curitiba e região metropolitana, esta pesquisa teve como objetivo desenvolver uma 
proposta onde fosse possível trabalhar de forma simplificada o aproveitamento do resíduos de MDF visando que estes não sejam descartados de forma incorreta.

Mesmo com pouco volume acumulado de resíduos em cada empresa, se somarmos estes ao um número significativo destas pequenas indústrias tem-se uma grande quantidade de resíduos. Assim, o desenvolvimento de uma alternativa de reutilização dos mesmos pode incentivar a ocupação de mão obra local, dando oportunidade de trabalho e novas opções de renda, seja através de mão de obra artesanal ou industrial, sem necessidade de muita tecnologia; apontando, ainda, caminhos que não prejudiquem o meio ambiente, contribuindo e aumentado o ciclo de vida desses materiais, que muitas vezes são descartados ou mal utilizados.

\section{Logística reversa, Economia circular}

$\mathrm{Na}$ atualidade é visível o aumento na preocupação com o ciclo de vida dos materiais utilizados na produção de bens, bem como a destinação dos resíduos gerados na transformação de matéria-prima e seus produtos finais. Sendo que a correta destinação de resíduos é algo cada vez mais cobrado tanto pelos órgãos fiscalizadores como pela sociedade.

As pequenas empresas de móveis muitas vezes empregam em sua produção familiares e equipamentos com pouca tecnologia. Sendo o modelo de produção em escala e sob medida temse uma quantidade de resíduos significativa, uma vez que seus projetos seguem medidas e formatos específicos, de acordo com as dimensões dos espaços de seus clientes.

[...] no segmento de móveis sob encomenda, cabe mencionar a presença de uma multiplicidade de micro e pequenas empresas, em geral marcenarias [...] seus equipamentos e instalações são quase sempre deficientes e ultrapassados - o que gera muitas imprecisões nas medidas - e o trabalho ainda é predominantemente artesanal (HILLING; SCHENEIDER; PAVONI, 2009, p. 299).

A reutilização dos resíduos provenientes do corte e usinagem de chapas de MDF pode se tornar uma oportunidade rentável tanto para empresas de móveis como também indústria de artesanatos e objetos de decoração.

Os resíduos de madeira podem ser utilizados tanto na produção de material combustível, na agricultura, na geração de energia elétrica em termoelétricas, na indústria de painéis reconstituídos e para a produção de pequenos objetos (ABREU et al., 2009, p. 174).

Contudo, além de se tornar uma opção a mais de reduzir custos e gerar uma fonte de renda, o reaproveitamento contribui para ciclo de vida prolongado do material, diminuindo o volume de resíduos descartados. Os resíduos de painéis de madeira podem ser aproveitados para a fabricação artesanal de pequenos objetos (POM). Os POM podem ter caráter utilitário ou decorativo, podem ser de uso pessoal, como brinquedos entre outros (ABREU et al., 2009).

A falta de espaço nas empresas, aterros sanitários cheios, pouca política de reciclagem e o desinteresse no reaproveitamento de resíduos devido ao alto custo financeiro e tecnologia disponível está se tornando uma grande preocupação da sociedade.

A extração de matéria-prima da natureza, os processos de transformação, o consumo e descarte exacerbado de materiais e produtos que poderiam ser aproveitados e utilizados por um período de vida mais longo contribuem para o volume de resíduos descartados ao meio ambiente, causando impactos irreversíveis nos ecossistemas existentes. 
Segundo Oliveira (2009), todas as organizações governamentais e não governamentais (nacionais e internacionais), associações comerciais e cientificas em conjunto com as indústrias têm que divulgar a produção limpa, através da informação consciente, seja através da educação ou treinamento. Desta forma, para se falar sobre o conceito de economia circular, é preciso lembrar às empresas do setor para a conscientização ambiental:

\begin{abstract}
Porém, o ser humano adotou uma abordagem linear, onde tudo é extraído, produzido e jogado fora. Isto, cada vez mais, desequilibra essa balança e torna difícil a recuperação do ecossistema. [...] Se eu chego ao final do processo e, pós-uso pelo consumidor, não consigo desviar este resíduo de aterro ou incineração, então eu devo voltar ao início do processo e refazer meu produto [....] da maneira como nosso sistema e processos estão concebidos hoje, tem sido caro separar e reciclar os materiais colocados no mercado. (PORTAL REVISTA DE MÓVEIS DE VALOR, 2016, s/p.).
\end{abstract}

Um exemplo de empresa do setor que tem dado atenção a esse novo conceito de economia circular, dando um fim sustentável aos resíduos gerados no processo produtivo, é a Artely, de São José dos Pinhais (PR). A fabricante implantou um projeto de reciclagem e reutilização de resíduos que servem de matéria-prima para outras indústrias da região.

É preciso pensar que toda essa cadeia não acontece sozinha, em apenas um grupo, mas sim um sistema integrado entre todos os setores da cadeia, como com as empresa que extraem matériaprima da natureza - madeiras naturas ou de manejo - e transformam em chapas lineares, passando aos fabricantes de móveis, que recebem as chapas e no processos de fabricação de móveis e outros objetos geram resíduos, sobras, até o consumidor final, que adquire o móvel e precisa dar um destino final adequado a este depois de passado o tempo de vida útil do mesmo.

A colaboração entre diferentes setores pode gerar soluções inovadoras, isso porque há casos em que os segmentos são distintos, mas os problemas são comuns. [...] A inovação não se faz mais sozinho e isolado em um setor. Centros de pesquisas, indústria plástica e química, laboratórios, universidade, tecnologia da informação, fashion design, materiais, tecidos, comunicação e formação são segmentos que valem a pena ficar de olho. (PORTAL REVISTA DE MÓVEIS DE VALOR, 2016, s/p.).

De acordo com uma pesquisa realizada via internet pelo grupo TNS (The Natural Step) que recebeu o título Our Green World (2008), com em média 13mil pessoas em diversos países, incluindo - Brasil, as questões ambientais influenciam diretamente na decisão de compra de $52 \%$ dos consumidores brasileiros, sendo que $83 \%$ estariam dispostos a pagar mais por produtos e serviços ecologicamente corretos.

Ainda nesta mesma pesquisa, a maioria dos latino-americanos acredita no comprometimento das empresas com a "causa verde" e com o meio ambiente (OLIVEIRA, 2009).

\title{
3 Características do setor moveleiro
}

O Estado do Paraná possui um mercado interessante para a instalação de fábricas do setor moveleiro, com mão de obra qualificada, além de cadeia produtiva densa e consolidada, também contém uma extensa gama de fornecedores para os diversos níveis do processo produtivo, disponibilidade de insumos e forte mercado consumidor.

O Paraná possui o segundo maior polo moveleiro do Brasil, com aproximadamente 14 mil micros, pequenas e médias empresas de capital nacional, localizadas, em sua maioria, na região 
centro-sul do país.

De acordo com o Sindicato das Indústrias de Móveis de Araponga (SIMA), o setor produziu 476,2 milhões de peças acabadas em 2013, o que representa um aumento de $3,4 \%$ em comparação com 2012. No período de 2009 a 2013 o crescimento foi de 28,7\%, representando alta média de $6,5 \%$ ao ano.

Dentro deste panorama, é importante pontuar que Curitiba e região metropolitana possuem um percentual de $46 \%$ da população economicamente ativa de todo Estado, além de apresentar grande número de cursos e formação educacional técnica para produção moveleira, como também na formação de graduação e pós-graduação para área de design técnico em móveis.

O Paraná possui inúmeras incubadoras e instituições de desenvolvimentos tecnológicos que atuam na transferência de conhecimentos científicos e tecnológicos, contribuindo para desenvolvimentos das empresas no intuito de que estas estejam continuamente atualizadas e inseridas no mercado nacional e internacional (BRASIL4BUSINESS, 2016).

Os produtos do setor são bastante diversificados, tendo maior incidência cozinhas, quartos e salas, todavia existe uma subdivisão. Conforme Herbst (2016), móveis de vime e assemelhados e móveis sob medida com utilização de madeira maciça e grande utilização de painéis de madeira (MDF, MDP, etc.), onde também são utilizados outros tipos de materiais, em especial os metais, principalmente na linha de móveis para escritórios.

Mesmo existindo alternativas para prolongar a vida útil dos resíduos provenientes do corte e transformação de chapas de madeira linear MDF e MDP através de redesign que poderiam contribuir para diminuição do descarte direto ao meio ambiente e uso através da queima para geração de energia - já que produtos como o MDF e o MDP possuem grande quantidade de produtos químicos na sua composição, que podem se tornar altamente prejudiciais à saúde e ao meio ambiente -, cada empresa tem que encontrar o seu caminho.

O crescimento no cenário atual no setor moveleiro pode estar associado a oportunidades no mercado externo ou a oportunidades criadas por reposicionamentos internos, discernir sobre os novos caminhos exige estar bem informado.

Segundo a Associação Brasileira da Indústria de Painéis de Madeira (Abipa), o setor de painéis de madeira vem apresentando taxas de crescimento de em média $10 \%$ ao ano. $O$ consumo de MDF no mercado brasileiro passou de 1,4 milhões de metros cúbicos por ano em 2005 para 3,2 milhões em 2010.

Por outro lado, segundo o Instituto Nacional de Combate ao Câncer (INCA), o formaldeído presente nos materiais de construção, como tintas, vernizes e colas - utilizados para a fabricação de edificações do tipo wood frame, móveis e painéis decorativos, principalmente aqueles que utilizam madeira composta - na forma gasosa é perigoso, podendo provocar lacrimação, severa sensação de queimação, tosse, permitindo ser tolerada por apenas alguns minutos. Este mesmo composto químico que causa reações adversas em quem manuseia os materiais pode ser liberado na atmosfera por longos períodos de tempo, sendo então um problema ambiental.

Para resolver isso o eco design se apresenta, ao mesmo tempo, como ferramenta e processo que tem a importância de envolver toda esta cadeia que engloba a necessidade, o espaço e seus resultados, sendo defino como: 
Eco design ou design ecológico é a abordagem ecológica de concepção e desenho, cuja finalidade é minimizar os impactos ambientais de um produto durante todo o seu ciclo de vida (KAZAZIAN, 2005, p. 46).

Desta forma, visando minimizar os impactos ambientais causados pelo descarte dos resíduos, o design contribui desenvolvendo novos produtos visando atender ao cliente de forma satisfatória. Bem como na preocupação com a escolha da matéria-prima a ser utilizada, observando qual recurso natural utilizado na produção, seu tempo de esgotamento natural, se é um recurso renovável, qual o tempo de duração que esse móvel deverá ter de acordo com o a expectativa de uso, se sua reciclagem é viável e possível, dentre outras preocupações.

\section{Levantamento de dados}

\subsection{Coletas de dados}

Em seguida será analisado como é feito o descarte dos resíduos proveniente do corte das madeiras. Sendo feita uma breve entrevista através do uso de um questionário, conforme exposto no Quadro 1, aplicado aos responsáveis das empresas visitadas, de forma verbal para a coleta de informações. Juntamente o provável interesse dos funcionários em reutilizar esses resíduos sólidos para construção de objetos decorativos, até mesmo de utilidades domesticas ou artesanais.

Quadro 1 - Questionário utilizado para a coleta de dados in loco

\begin{tabular}{|ll|}
\hline 1. & Nome da empresa? \\
\hline 2. & Cidade? \\
\hline 3. & No de empregados? \\
\hline 4. & Segmento? Móveis seriados ou móveis sob medida ou artesanato. \\
\hline 5. & Tempo de atuação no mercado? \\
\hline 6. & Tipo de mobiliário fabricado? Residências, comerciais, entre outros. \\
\hline 7. & Matéria-prima utilizada? MDF ou MDP \\
\hline 8. & Outra, qual? \\
\hline 9. & Faz plano de corte? Sim ou Não. \\
\hline 10. & Sistema de gestão ambiental? Sim ou Não. \\
\hline 11. & Se possui, qual? \\
\hline 12. & Total de resíduos de MDF? \\
\hline 13. & Total de resíduos de MDP? \\
\hline 14. & O que faz com os residuos de restos de chapas? Destino? \\
\hline 15. & Separa o tipo de resíduo? Sim ou Não. \\
\hline 16. Como? \\
\hline 17. Tamanhos dos residuos? (MDF, MDP) \\
\hline
\end{tabular}

FONTE: Elaborado pelos pesquisadores. 
Uma vez descobrindo o que é feito com esses resíduos sólidos será possível avaliar as condições atuais de descarte e o destino dos resíduos sólidos, bem como a maneira correta a se fazer.

A partir desta pesquisa, analisando o processo de descarte, será possível desenvolver e apresentar um novo método aproveitamento destes resíduos sólidos, retornando à cadeia de insumos.

\subsubsection{Pesquisa de campo: análise de geração de resíduos}

Neste capítulo são apresentados os depoimentos e figuras, referentes ao levantamento de dados, gerados a partir da pesquisa de campo in loco.

Levantando de quais são os tipos de sobras de chapas, MDF ou MDP, seus formatos, dimensões e a quantidades de resíduos sólidos gerados e disponíveis para transformação em pequenos produtos: móveis, artesanatos ou objetos de decoração.

Como é feito o armazenamento e reaproveitamento, dependendo do formato e dimensões para fins estruturais de novos móveis e objetos. Analisando qual o procedimento de descarte dos resíduos sólidos provenientes dos cortes das chapas: Descartado em aterro sanitário? Queima? Venda e para quem? Foram coletadas cinco entrevistas de empresas que atuam na área de marcenaria, mais especificamente na confecção de mobiliários.

A coleta de dados foi numerada de A, B, C, D, E, sendo em Curitiba e região metropolitana, utilizando questionário juntamente a uma entrevista ao responsável da empresa analisando os tipos de resíduos gerados nos processos de construção de móveis, como são armazenados, quantidades e qual processo de descarte ou reutilização é dado aos resíduos.

Os resíduos encontrados nas empresas estavam em boas condições de reaproveitamento, já que o armazenamento é feito em área coberta, livre de ações do tempo e contaminantes.

A empresa " $A$ ", identificada como Gavelik Marcenaria, possui três funcionários todos ligados direto à produção, sua linha é móveis residências sendo todos produzidos em MDF. O responsável informou que todos os resíduos são depositados em espaço único com um volume médio de um metro cúbico semanal. Sendo feito uma triagem das sobras de recortes para aproveitamento para partes estruturais em novos móveis. Na referida empresa o descarte é feito por coleta de terceiros que o destinam à queima para geração de energia.

Figura 1 - Resíduos da empresa "A"

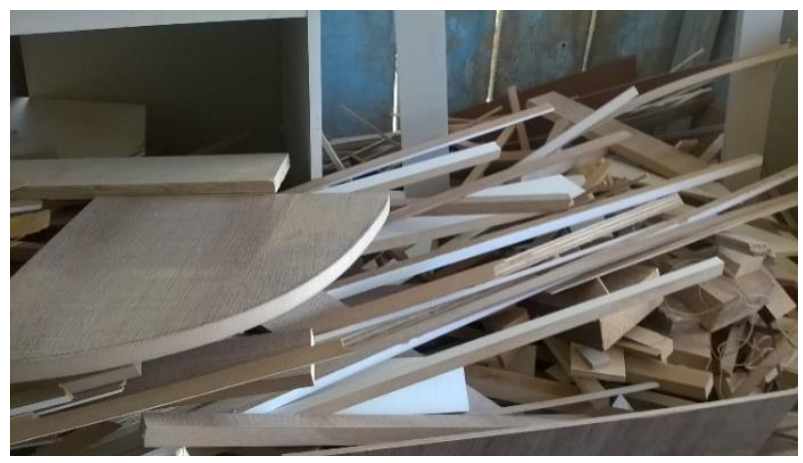

Fonte: Pesquisa de campo (2016). 
Na empresa "B", Daniel e Élcio Straiotto, possui dois funcionários, a empresa trabalha com madeiras apenas com MDF na produção de móveis residências. A quantidade de resíduos é relativamente pequena, sendo depositado em caixas plásticas e pequenos recipientes. Seu descarte é feito no lixo comum ou a queima dentro das dependências da própria empresa, já que seu volume em média é de meio metro cúbico mensal.

Figura 2 - Resíduos da empresa "B"

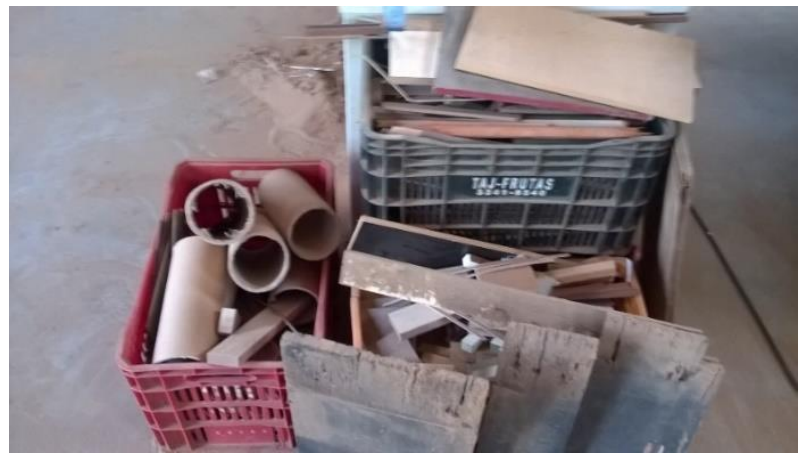

Fonte: Pesquisa de campo (2016).

A empresa " $C$ ", Straiotto Marcenaria, produz móveis em MDF e madeira natural, tanto na produção de móveis residenciais, como de decoração. Tendo uma produção em torno de 3 metros cúbicos mensal de resíduos que é armazenada dentro de tambores ou caixotes, sendo coletados por terceiros e destinada à queima para geração de energia. O aproveitamento se faz através de separação de peças e sobras que possam ser utilizadas na confecção de novos móveis e partes estruturais.

A empresa " $D$ ", Móveis Prado, uma marcenaria de pequeno porte que produz móveis somente em madeira reconstituída MDF por encomenda, sendo a maioria dos móveis produzidos são residenciais, não possui funcionários, pois o proprietário alega que seu fluxo mensal é pequeno, então não tem condições de arcar com um funcionário. Ele não faz anotações de quantos móveis são produzidos por mês, nem de quantos $\mathrm{m}^{3}$ de matéria-prima é utilizada. Os compradores dos móveis são moradores do bairro, geralmente aparecem por indicação de outros que já produziram com ele, as chapas de MDF que servem como matéria-prima são compradas em uma loja de Curitiba, chamada O Bicho Carpinteiro, e já vem cortadas.

A loja fornecedora utiliza de um sistema de plano de corte, aproveitando ao máximo a matéria-prima e evitando sobras, somente pequenos cortes são feitos na marcenaria pelo próprio proprietário, através do uso de uma serra circular. Por este motivo não gera muitos resíduos em pó, relatou o marceneiro que o saco da máquina onde armazena o pó leva quase um ano para encher, o modelo da máquina pode ser visto na Figura 3. 
Figura 3 - Máquina serra circula e coletor dos resíduos de pó da empresa “D”

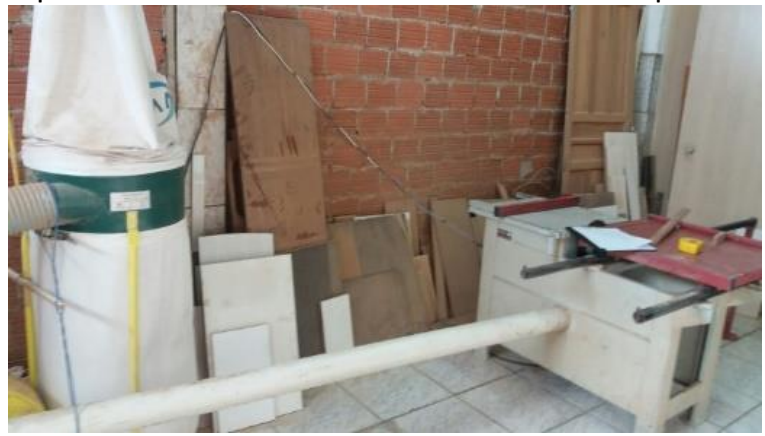

Fonte: pesquisa de campo (2016).

O descarte deste pó é feito de maneira inapropriada, descartado no outro lado da rua da marcenaria. As sobras de chapas que são cortadas no fornecedor, conforme Figura 4.

Figura 4 - Sobras de chapas cortadas no fornecedor da empresa " $D$ "

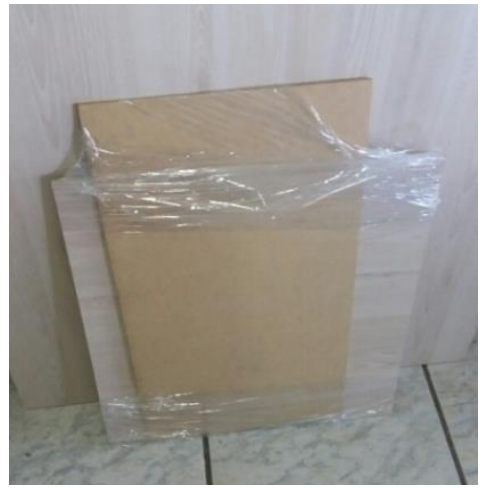

Fonte: Pesquisa de campo (2016).

As sobras de chapas são devolvidas para a marcenaria junto com as peças cortadas para a montagem dos móveis, as que sobram das chapas que medem a cima de $40 \times 20 \mathrm{~cm}$ são consideradas pelo marceneiro como resíduos aproveitáveis. Estes resíduos são separados e armazenados junto à parede conforme Figura 5.

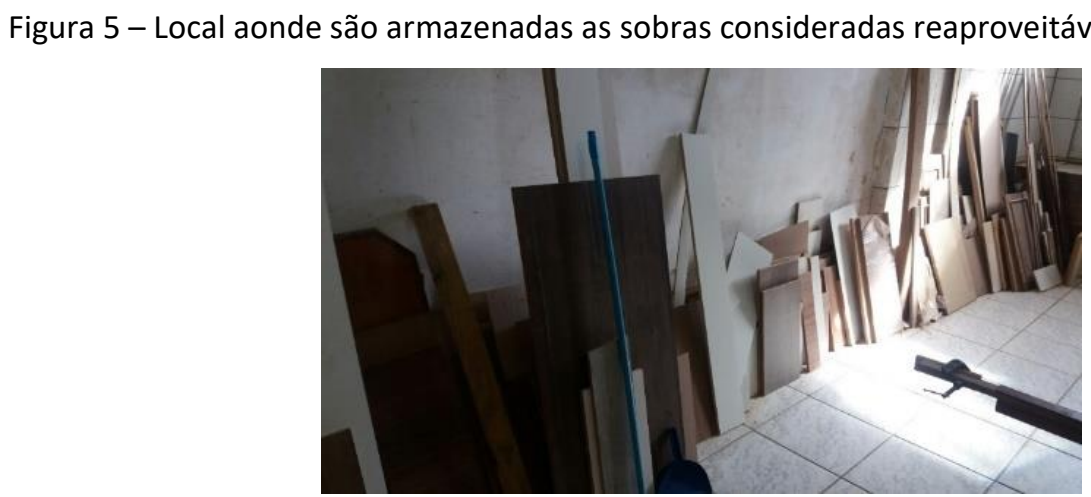

Fonte: Pesquisa de campo (2016).

Tais sobras são reaproveitadas na confecção de pequenas partes de móveis, como gavetas e partes estruturais, e no engrossamento destes. Porém, há sobras de chapas que são armazenadas por quase 4 anos por falta de oportunidade de reaproveitamento, o proprietário alega que gostaria de vender a maioria dessas sobras. Alguns pedaços ou retalhos medidos são $40 \times 13 \mathrm{~cm}, 28 \times 4 \mathrm{~cm}$, 
$50 \times 8 \mathrm{~cm}, 60 \times 2,5 \mathrm{~cm}, 10 \times 5 \mathrm{~cm}$ dentre outros tamanhos, essas variações de tamanhos são consideradas pelo o marceneiro pedaços não aproveitáveis, conforme pode-se ser visualizado na Figura 6.

Figura 6 - Sobras de variados tamanhos considerados não reaproveitáveis pela empresa " $D$ "

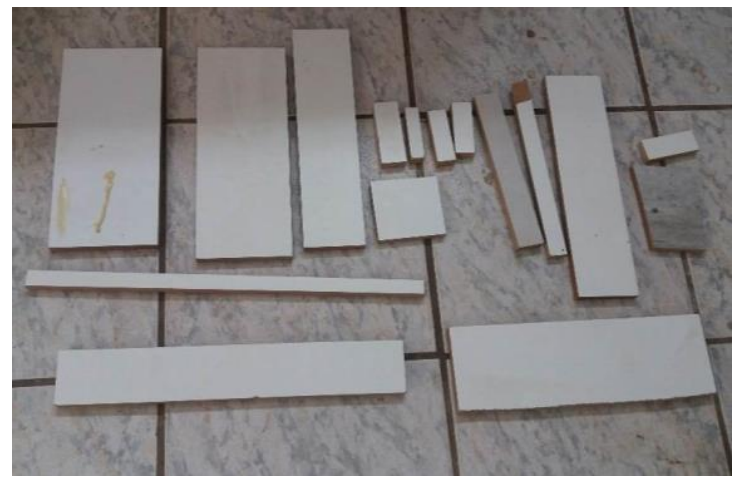

Fonte: Pesquisa de campo (2016).

Esses resíduos são armazenados em um móvel de madeira sob medida de 190x95×75cm, que também é o local de execução de algumas atividades, conforme Figura 7.

Figura 7 - Sobras que são consideradas não reaproveitadas pela da empresa “D”

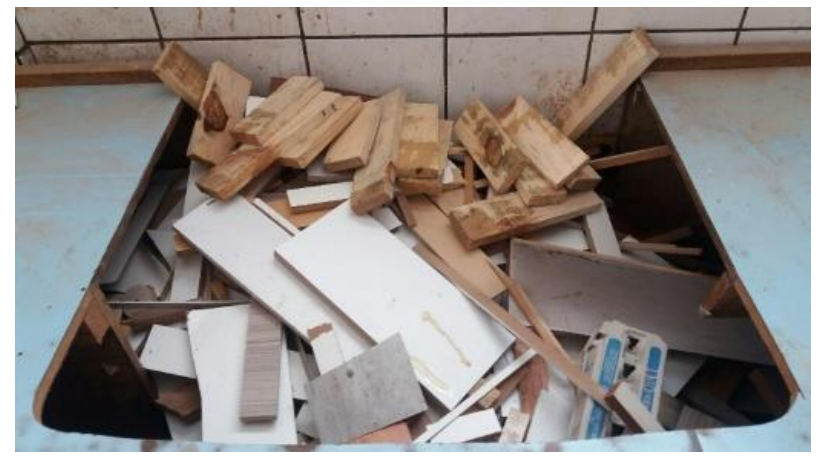

Fonte: pesquisa de campo (2016).

Dentre as sobras rejeitadas, algumas são armazenadas por em média 1 ano por não terem nenhum destino, sendo então coletadas por terceiros, amigos ou vizinhos, os quais utilizam-nas na queima para acender churrasqueiras e lareiras. O proprietário reclama de não ter uma opção adequada para doar esses pedaços que ele considera inaproveitáveis para o seu ramo de atividade, mas que muitos desses estão em ótimo estado de conservação e poderiam ser reaproveitados, porém, ele não conhece nenhum interessado, por este motivo acaba dando um destino inadequado aos seus resíduos, somente por falta de opção.

A empresa "E" é uma marcenaria informal e familiar de pequeno porte, fundo de quintal, localizada em um bairro de Curitiba/PR, atua no mercado há 14 anos, o entrevistado não permitiu apontar a localização, os mobiliários produzidos são todos em chapas de madeira reconstituída MDF, esses mobiliários são produzidos sob medida e apenas por encomenda, sendo em sua maioria móveis produzidos residenciais. Nesta marcenaria trabalham 5 pessoas, pai e filhos. Eles não 
possuem anotações sobre sua produção mensal, somente calculam aproximadamente mensalmente, $R \$ 5,000,00$ de gastos com as chapas em madeira reconstituída MDF.

O processo de corte dessas chapas de MDF é feito na própria marcenaria, com o uso de uma serra circular sem auxílio de software de plano de corte, sendo este feito de forma manual, não possuindo um aproveitamento total das chapas, gerando então grande desperdício de chapas, com sobras muitas vezes de tamanho grande.

Os resíduos que medem acima de 1 metro de comprimento por no mínimo $5 \mathrm{~cm}$ de largura são considerados reutilizáveis, esses mais estreitos são para confeç̧ão de engrossamento dos mobiliários e partes estruturais. Muitas das sobras possuem tamanhos grandes, mais que 1 metro de comprimento por mais de $60 \mathrm{~cm}$ de largura, sendo então utilizadas para confecção de várias partes de mobiliários. Todas as sobras consideradas reutilizáveis são separadas e armazenadas em duas das paredes da marcenaria, conforme Figuras 8 e 9.

Figura 8 - Parede 1, local de armazenamento das sobras consideradas reaproveitáveis pela empresa " $\mathrm{E}$ "

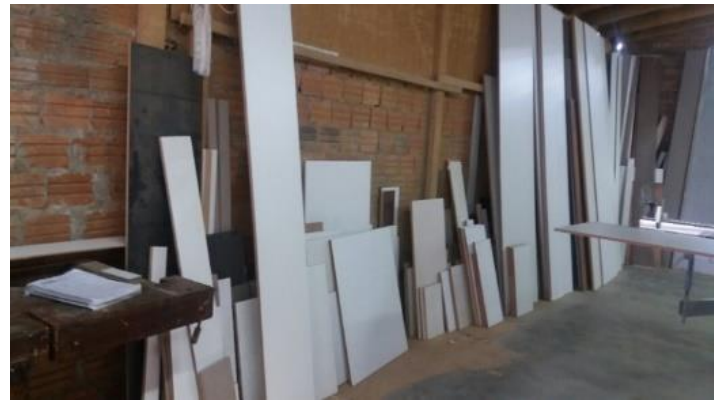

Fonte: Pesquisa de campo (2016).

Figura 9 - Parede 2, local de armazenamentos das sobras consideradas reaproveitáveis pela empresa "E"

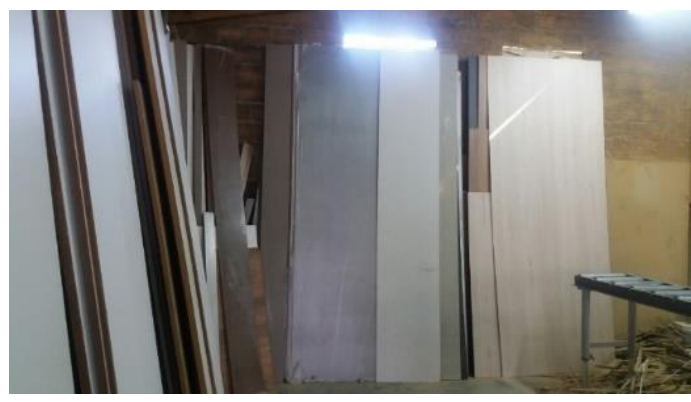

Fonte: Pesquisa de campo (2016).

Os resíduos que são considerados inutilizáveis ficam expostos no chão entre os maquinários, conforme Figura 10 e 11. 
Figura 10 - local onde são armazenadas as sobras consideradas não reaproveitáveis pela empresa "E"

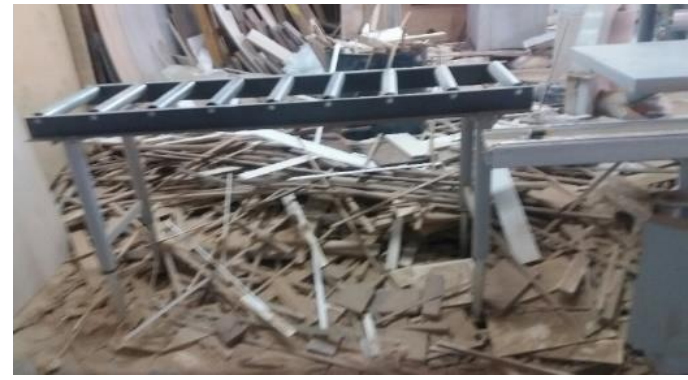

Fonte: Pesquisa de campo (2016).

Figura 11 - Local onde são armazenadas as sobras consideradas não reaproveitadas pela empresa "E"

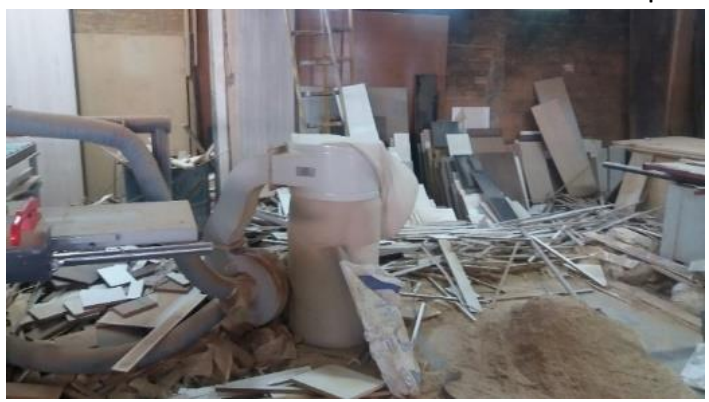

Fonte: Pesquisa de campo (2016).

A quantidade de resíduos é bem considerável, conforme o "amontoamento" de resíduos vai se tornando inapropriado ao uso do espaço e atrapalhando a circulação são ensacados em sacos de lixo reforçados e colocados na calçada para que serem levados por quem por eles se interessar.

O marceneiro reclama de não ter um destino adequado para o descarte desses resíduos, sabe que é proibida a queima, mas não tem opção de fazer um descarte adequado, onde esses resíduos poderiam ser reaproveitados em outros tipos de produtos, por estarem em ótimo estado de conservação e, geralmente, terem tamanhos bons para o reuso, poderiam ser para confecção de pequenos produtos, entre as sobras foram encontrados tamanhos de: $1 \mathrm{~m}$ por $5 \mathrm{~cm}, 15 \times 5 \mathrm{~cm}, 20 \times 20$ $\mathrm{cm}$, entre outros, conforme Figura 12.

Figura 12 - Tamanhos variados de sobras não reaproveitadas pela empresa "E"

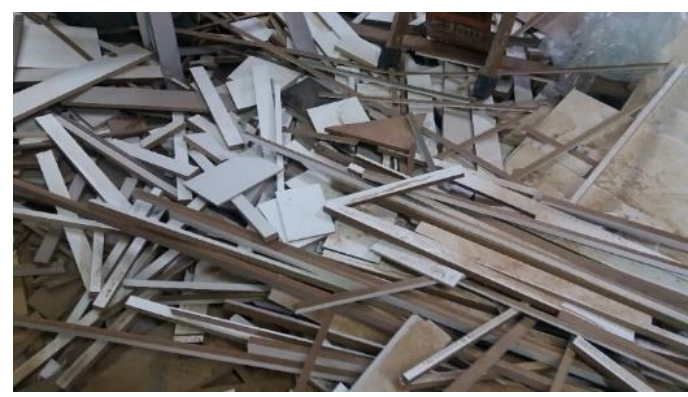

Fonte: Pesquisa de campo (2016).

\subsection{Reaproveitamento de resíduos sólidos através do eco design e economia circular}

A sociedade tem estado cada vez mais preocupada em adquirir produtos de empresas que se preocupam com a questão ambiental em sua produção. Um dos mecanismos que as empresas 
têm usado para adaptar seus produtos e processos é o desenvolvimento de novas propostas em harmonia com o meio ambiente, desde a extração da matéria-prima na natureza até o descarte final. Este processo se dá através da aplicação do eco design, que vem justamente com intuito de reduzir os impactos causados pelo processo de transformação de produtos.

O termo Eco design refere-se à inclusão da variável ambiental nas diferentes etapas de projeto, desenvolvimento e execução de produtos, processos ou serviços, com o objetivo de minimizar o impacto ambiental das atividades envolvidas. A redução do impacto ambiental é obtida pela adoção de princípios tais como: utilização de materiais de baixo impacto ambiental, busca pela eficiência energética, qualidade e durabilidade, adoção de técnicas de modularidade, assim como reutilização e o reaproveitamento (BRONES, 2014).

Isso faz com que se possa prolongar o tempo de uso destes produtos, ao mesmo tempo em que possibilitam incluir um retorno ao seu próprio ciclo. Este processo vem a atender a Política Nacional de Resíduos Sólidos (PNRS) criada com a Lei no. 12305/2010, cujo propósito é atender ao objetivo do ciclo de caminho inverso, onde há o reaproveitado em novos processos de produção e produtos. Essa alternativa faz com que surjam efeitos positivos em favor das empresas, diminuindo a quantidade de matéria-prima, seus processos, logística de distribuição, coleta e gerenciamento de resíduos sólidos.

Dentro da concepção do eco design está envolvida a economia circular, que é a ciência que se preocupa com o desenvolvimento sustentável aumentando a eficiência na criação de produtos e reaproveitamento de resíduos sólidos. Área que mais cresce devido à necessidade de aproveitar melhor os recursos naturais e não causar tantos impactos ao meio ambiente.

Entre seus objetivos, a economia circular se preocupa basicamente em conceber produtos utilizando materiais que possam ser facilmente recicláveis e que seus resíduos sólidos possam ser reintroduzidos na cadeia produtiva. Objetivo este que conversa com um dos problemas de grande parte das pequenas e médias fábricas de móveis, que é a dificuldade de dar um aproveitamento e descarte correto de resíduos gerados.

O Sindicato da Indústria do Mobiliário e Marcenaria do Estado do Paraná (SIMOV) está trabalhando para o desenvolvimento de uma central de resíduos na região de Curitiba para o setor moveleiro que propõe uma linha de trabalho a ser desenvolvida, sobre isso, segundo o sindicato, "[...] as indústrias precisam de um planejamento no processo produtivo do antes e depois". Ainda segundo dados do SIMOV a indústria da madeira descarta 122 das 144 toneladas de materiais das indústrias moveleiras do Paraná, desta forma a central, além garantir correta destinação dos resíduos da indústria moveleira, abrirá possibilidade para o estudo de novas soluções e utilizações para estes materiais descartados.

Através da pesquisa e análise realizada na reutilização das sobras de matéria-prima (chapas de madeira reconstituída MDF) e resíduos sólidos gerados nas pequenas fábricas de móveis de Curitiba e região metropolitana foi possível verificar que não existe interesse nem conhecimento informativo suficiente para que se desenvolva uma proposta de reaproveitamento das sobras de corte, seja em plano de gestão de resíduos ou projetos para produção de objetos de decoração, de utilidade doméstica, ou seja, envolvendo área de criação e design através de estudos ou projetos para direcionar os responsáveis das marcenarias desta pesquisa. Uma vez que na equipe que integra o pessoal da produção das empresas visitadas, geralmente, são o proprietário e membros de sua família, tendo apenas os conhecimentos técnicos de equipamentos de marcenaria, sem qualquer 
formação especifica técnica ou acadêmica na área de Design ou projetos. Nota-se ainda que muitos dos projetos e serviços assumidos por essas fábricas são apenas de orçamento e confecção de mobiliários que, na maioria das vezes, são confeccionados a partir de croquis, não muito técnicos, ou mesmo recebem projetos prontos de arquitetos e designers que atuam na área da concepção junto ao cliente.

\section{Conclusões}

Em observação in loco nas empresas de pequeno porte visitadas, juntamente à análise da coleta de dados, foi possível identificar a quantidade de resíduos produzidos, seu aproveitamento e como é feito o descarte. Verificando que na maioria dessas empresas não faz uso de software de corte apropriado e nem de maquinário de controle numérico computadorizado (CNC) por serem pequenas e com pouco fluxo de fabricação, mas a quantidade de resíduos gerados é relativamente considerável, uma vez que todas essas empresas visitadas utilizam as chapas de madeira reconstituída MDF como matéria-prima.

Ademais, nota-se que a forma de reuso dos resíduos considerados reaproveitáveis dentro dessas empresas é para sua própria produção, mas ocorre um acúmulo grande de estocagem, levando um tempo grande de armazenamento, passando até de 4 anos no mesmo local, ocupando espaço, podendo causar acidentes de trabalho. Todavia, o mais preocupante é o descarte inapropriado quando poderia ser dado um destino mais adequado, visto que essas sobras de matéria-prima podem ser consideradas reutilizáveis por estarem em ótimo estado de conservação e possuírem tamanhos bons para o aproveitamento em novos produtos.

Porém, por não existir projeto ou processo de reaproveitamento destes resíduos, nem interesse ou mesmo incentivo em dar um destino mais adequado a estes resíduos, foi verificado que nessas empresas visitadas, segundo informado pelos seus responsáveis, inexistem interessados em utilizar os resíduos para confecção de produtos, sejam outro nicho de mercado na fabricação industrial ou artesanal. Isso talvez se dê pelo fato de haver baixo valor de revenda, ao tempo necessário para se produzir, bem como pessoal adequado para estudos e desenvolvimentos de projetos. Então se pode concluir que existe uma expressiva demanda quanto à possibilidade e necessidade de reaproveitamento destes resíduos, já que suas proporções dimensionais possibilitam a construção de variados produtos, como objetos de decoração, de utilidade doméstica, para escritório, brinquedos entre outros fins, o que contribuiria para prolongar o tempo de ciclo de vida deste material, diminuindo a quantidade e o prejuízo ambiental do descarte inapropriado.

\section{Referências}

ABREU, L. B.; MENDES, L. M.; SILVA, J. R. M. Aproveitamento de resíduos de painéis de madeira gerados pela indústria moveleira na produção de pequenos objetos. Revista Árvore, Viçosa, v. 33, n. 1, p. 171-177, 2009.

BRITO, L. S.; CUNHA, M. E. T. Reaproveitamento de Resíduos da Indústria Moveleira. UNOPAR Cient. Exatas Tecnol., Londrina, v. 8, n. 1, p. 23-26, Nov. 2009. Disponível em: <http://www.pgsskroton.com.br/seer/index.php/exatas/article/viewFile/619/588>. Acesso em: 16 
nov. 2016.

BRONES F.; CARVALHO M. M.; ZANCULE. S. Ecodesign in project management: a missing link for the integration of sustainability in product development. Journal of Cleaner Production, p. 1-13, June, 2014.

CASSILHA, A. C.; PODLASEK, C. L.; CASAGRANDE, E. F. J.; DA SILVA, M. C.; MENGATTO, S. N. F. Indústria moveleira e resíduos sólidos: considerações para o equilíbrio ambiental. Revista Educação \& Tecnologia. Curitiba, Editora do CEFETPR, v. 8, p. 209-228, 2004. Disponível em: $<$ http://www.utfpr.edu.br/curitiba/estrutura-

universitaria/diretorias/dirppg/grupos/tema/25indus_moveleira_ambiental.pdf/view>. Acesso em: 16 nov. 2016.

HERBST, Elcio, Diagnose da gestão de resíduos sólidos no setor moveleiro da RMC e contribuições para o projeto da central de resíduos. Dissertação. Mestrado Profissional em Meio Ambiente Urbano e Industrial. 133f. Curitiba. Universidade Federal Do Paraná - Senai Departamento Regional do PR - Universidade De Stuttgart, 2001.

HILLING, É.; SCHNEIDER, V. E.; PAVONI, E. T. Geração de resíduos de madeira e derivados da indústria moveleira em função das variáveis de produção. Production Journal, v.19, n.2, p. 292-303, 2009. Disponível em: <http://www.prod.org.br/doi/10.1590/S0103-65132009000200006>. Acesso em: 09 dez. 2016.

KAZAZIAN, T. Haverá a Idade das Coisas Leves: Design e Desenvolvimento Sustentável. São Paulo: Ed. Senac, 2005.

$\mathrm{KOCH}$, G.S., KLAREICH, F., EXSTRUM, B. Adhesives for the composite wood panel industry. Ed. Noyes Data Corporation. New Jersey. U.S.A., 1987.

LIMA, E. G. de ; SILVA, D. A. da. Resíduos gerados em indústrias de móveis de madeira situadas no pólo moveleiro de Arapongas-PR. Revista Floresta, Curitiba, PR, v.35,n. 1, jan./abr. 2005. Disponível em: <http://revistas.ufpr.br/floresta/article/view/2434/2036>. Acesso em: 16 nov. 2016.

OLIVEIRA, Rosimery de Fátima. Visão integrada em meio ambiente, CNI e SENAI-PR, 2009.

PORTAL MÓVEIS DE VALOR. Economia circular no setor: especialista fala sobre o conceito e faz alerta às empresas do setor para a conscientização ambiental. Publicado em 04/10/2016. Disponível em: <http://moveisdevalor.com.br/portal/economia-circular-no-setor-moveleiro>. Acesso em: 16 nov. 2016

RAPÔSO, A.; KIPERSTOK, A.; CÉSAR, S. F. Produção mais limpa e design do ciclo de vida de móveis estofados no Estado de Alagoas, Brasil. In: 3rd International Workshop Advances in Cleaner Production, 2011, São Paulo: UNIP, 2011.

SCHUSTER, Moreira; Estefanie. Uma perspectiva sobre o design e a produção de móveis sob encomenda: uso e o descarte de painéis de fibra de madeira de média densidade. Dissertação. Mestrado em Design. 212f. Curitiba. Universidade Federal do Paraná, 2013.

WEBER, Cristiane. Estudo sobre viabilidade de uso de resíduos de compensados, mdf e mdp para produção de painéis aglomerados. Dissertação. 90f. Programa de Pós-graduação em Engenharia Florestal, Setor de Ciências Agrárias. Curitiba. Universidade Federal do Paraná, 2011. 